\title{
Inhibition of p38 MAPK increases the sensitivity of 5-fluorouracil-resistant SW480 human colon cancer cells to noscapine
}

\author{
ZHENG HAN*, LIU MENG* ${ }^{*}$ XIAODONG HUANG, JIE TAN, WEIJIE LIU, WEI CHEN, YANLI ZOU, \\ YISHAN CAI, SHASHA HUANG, AIFANG CHEN, TING ZHAN, MIN HUANG, \\ XIAOLI CHEN, XIA TIAN and QINGXI ZHU
}

Department of Gastroenterology, Tongren Hospital of Wuhan University

(Wuhan Third Hospital), Wuhan, Hubei 430060, P.R. China

Received December 16, 2020; Accepted May 12, 2021

DOI: $10.3892 / \mathrm{ol} .2021 .13170$

\begin{abstract}
A major cause of treatment failure in advanced colon cancer is resistance to chemotherapy. p38 mitogen-activated protein kinase (MAPK) has been associated with cellular apoptosis and plays an important role in multidrug resistance (MDR) in cancer cells. In the present study the effect of p38 MAPK on the sensitivity of 5-fluorouracil (5-FU)-resistant SW480 (SW480/5-FU) human colon cancer cells to noscapine was investigated. Following p38 MAPK interference, the inhibitory effect of noscapine on cell viability and proliferation was increased in the SW480/5-FU cells and there was also a decrease in the expression level of minichromosome maintenance proteins, recombinant $\mathrm{Ki}-67$ and proliferating cell nuclear antigen. Inhibition of p38 MAPK also enhanced noscapine-induced $\mathrm{G}_{1}$-phase cell cycle arrest in the SW480/5-FU cells and there was also a decrease in the protein and mRNA expression level of cyclin D, cyclin E and cyclin-dependent kinase 2, and an increase in the expression level of P57. Furthermore, p38 MAPK interference increased noscapine-induced apoptosis of the SW480/5-FU cells and there was an increase in the protein and mRNA expression level of caspases-3 and 8 and Bax, and decreased Bcl-2
\end{abstract}

Correspondence to: Dr Qingxi Zhu or Dr Xia Tian, Department of Gastroenterology, Tongren Hospital of Wuhan University (Wuhan Third Hospital), 241 Pengliuyang Road, Wuhan, Hubei 430060, P.R. China

E-mail: 12858590@qq.com

E-mail: hewy100@163.com

*Contributed equally

Abbreviations: MAPK, mitogen-activated protein kinase; MDR, multidrug resistance; ABC, ATP-binding cassette; 5-FU, 5-fluorouracil; MRP1, multidrug resistance protein 1; P-gp, P-glycoprotein; CCK-8, Cell Counting Kit-8

Key words: colon cancer, drug resistance, noscapine, p38 MAPK, apoptosis expression level. The sensitivity of the SW480/5-FU cells to noscapine was also increased following p38 MAPK interference, as demonstrated by MDR inhibition via decreased Akt activity and reduced protein expression level of the MDR proteins P-glycoprotein, multidrug resistance protein 1 and ATP-binding cassette G2. These observations indicated that inhibition of p38 MAPK increased the sensitivity of the SW480/5-FU cells to noscapine by suppressing proliferation, induction of cell cycle arrest and apoptosis, and reversal of MDR in the SW480/5-FU cells.

\section{Introduction}

Colon cancer is one of the most common types of cancer worldwide and ranks 3rd with respect to mortality worldwide (1). In China, colon cancer has the highest incidence and mortality rates compared with that in other types of cancer, including ovarian and bladder cancers (2) and remains a major therapeutic challenge despite advancements in systemic therapies (3). With the repeated use of traditional chemotherapy in clinical practice, tumor cells gradually acquire resistance to chemotherapeutic drugs with different structures and functions. This development of multidrug resistance (MDR) limits the effectiveness of chemotherapeutic drugs in killing the tumor cells. The mechanisms underlying drug resistance in cancer cells are complex and remain poorly understood. The most commonly studied mechanism of MDR is overexpression of ATP-binding cassette (ABC) transporters, which decrease drug accumulation in cancer cells (4). The most extensively studied MDR transporters include MDR1, P-glycoprotein (P-gp), MDR protein 1 (MRP1) and ABCG2. These transport proteins have been reported to be targets for antitumor therapy in drug-resistant tumors $(5,6)$. The chemotherapeutic drug, 5-fluorouracil (5-FU) is widely used to treat colon cancer (7); however, long-term exposure of the cancer cells to 5-FU results in chemoresistance (8). Therefore, the development of new drugs to overcome chemoresistance has become an important topic in current cancer research.

Noscapine, a phthalide isoquinoline alkaloid derived from opium, has been used as an oral anti-tussive agent with few 
toxic effects in animals and humans $(9,10)$. The chemical structure of noscapine is similar to that of the microtubule inhibitor colchicine and its inhibitory effect on microtubules has been widely recognized (11). Noscapine binds stoichiometrically to tubulin, alters its conformation, affects microtubule assembly and arrests mammalian cells in mitosis (10). At present, noscapine is in phase I/II clinical trials for the treatment of low-grade non-Hodgkin's lymphoma, chronic lymphocytic leukemia refractory to chemotherapy and other hematological malignancies. Noscapine has been found to inhibit the proliferation of various cancer cells, including prostate cancer, breast cancer and ovarian cancer, and numerous drug-resistant variants, while evading normal cells (12). Our previous studies confirmed that noscapine induced partial tumor cell apoptosis via mitochondrial pathways $(13,14)$. In addition, noscapine was effective against tumor growth of human breast cancer, murine lymphoma and melanoma in nude mouse models with little or no toxicity in the spleen, liver, heart and kidney $(10,15,16)$. However, the potential mechanisms of noscapine in enhancing sensitivity and overcoming resistance of tumor cells to traditional chemotherapeutic drugs are still unclear.

The mitogen-activated protein kinase (MAPK) signaling pathway plays an important role in cell proliferation, differentiation, survival and apoptosis (17), and has been associated with anti-apoptosis and chemoresistance development in colon cancer (18). Furthermore, MAPK has been shown to be aberrantly activated in patients with colon cancer (19). p38 MAPK is an important part of the MAPK pathway and has been associated with cancer cell survival, and inhibition of p38 MAPK was found to enhance the cytotoxic effects of 5-FU on colorectal cancer cells (20). However, the role and mechanism of the p38 MAPK signaling pathway in the regulation of chemoresistance in colon cancer by noscapine is unknown. The present study was designed to identify the effect of p38 MAPK on the sensitivity of 5-FU-resistant SW480 colon cancer cells to noscapine.

\section{Materials and methods}

Chemicals and cell culture. Noscapine was purchased from Abcam (cat. no. ab215525), and 5-FU was purchased from Shanghai Aladdin Biochemical Technology Co., Ltd (cat. no. F100149). The human SW480 colon cancer cell line was purchased from the China Center for Type Culture Collection, cultured in RPMI-1640 medium (Gibco; Thermo Fisher Scientific, Inc.), supplemented with $10 \%$ FBS (Bioswamp) and maintained in a humidified incubator with $5 \% \mathrm{CO}_{2}$, at $37^{\circ} \mathrm{C}$. The 5-FU-resistant SW480 cell line (SW480/5-FU) was established as previously described (21), using $2.0 \mu \mathrm{g} / \mathrm{ml} 5-\mathrm{FU}$.

The SW480/5-FU cells were divided into 5 groups: No treatment (SW480/5-FU); transfection with empty vector (SW480/5-FU+EV); treatment with $25 \mu \mathrm{mol} / 1$ noscapine (SW480/5-FU+Nos); transfection with p38 interference vector (SW480/5-FU+si-p38) and combined transfection with p38 interference vector and treatment with $25 \mu \mathrm{mol} / 1$ noscapine (SW480/5-FU+Nos+si-p38). Untreated, non-resistant SW480 cells served as the control group.

p38 MAPK interference. The mRNA expression level of p38 MAPK was silenced using small interfering (si)RNA
(100 pmol). The p38 MAPK interference fragment (si-p38; 5'-CCAGACCATTTCAGTCCAT-3') and the negative control (si-NC, a scramble sequence) were transfected into the SW480/5-FU cells using Lipofectamine ${ }^{\circledR} 2000$ (cat. no. 11668-027; Invitrogen; Thermo Fisher Scientific, Inc.), according to the manufacturer's instructions at $37^{\circ} \mathrm{C}$ for $48 \mathrm{~h}$, before subsequent experiments.

Cell Counting Kit-8 (CCK-8) assay. Cell proliferation was analyzed using the CCK-8 assay (cat no. PAB180031; Bioswamp; Wuhan Bienle Biotechnology Co., Ltd.). The cells were seeded in 96-well plates, at a density of $1 \times 10^{4}$ cells/well. CCK-8 solution ( $10 \mu \mathrm{l})$ was added to each well after $24 \mathrm{~h}$, then the cells were incubated for $4 \mathrm{~h}$, at $37^{\circ} \mathrm{C}$. Absorbance was measured at $450 \mathrm{~nm}$. The assays were repeated 3 times.

Colony formation assay. To investigate colony formation, the cells were seeded in 6-well plates (600 cells/well) and maintained in RPMI-1640 medium supplemented with $10 \% \mathrm{FBS}$ at $37^{\circ} \mathrm{C}$. The medium was replaced every 3 days. After 14 days, the colonies were fixed with methanol at $4^{\circ} \mathrm{C}$ for $15 \mathrm{~min}$ and stained with $0.1 \%$ crystal violet for $30 \mathrm{~min}$ at $4^{\circ} \mathrm{C}$ (Sigma-Aldrich; Merck KGaA). Visible colonies were manually counted, and triplicate measurements were performed for each treatment group.

Cell cycle analysis. For cell cycle analysis, a total of $5 \times 10^{4}$ cells were collected and washed 3 times with PBS. The cells were then incubated in a solution containing $500 \mu \mathrm{g} / \mathrm{ml} \mathrm{PI}$ and $100 \mu \mathrm{g} / \mathrm{ml}$ RNase A for $30 \mathrm{~min}$ at $4^{\circ} \mathrm{C}$ and subsequently analyzed using flow cytometry (NovoCyte; Agilent Technologies, Inc.), and the data were analyzed using CytExpert software (version 2.0; Beckman Coulter, Inc.). Each measurement was performed at least three times.

Cell apoptosis assay. Cell apoptosis was measured using an Annexin V-fluorescein isothiocyanate (FITC)/PI flow cytometry kit (BD Biosciences) according to the manufacturer's instructions. The cells were washed with ice-cold PBS 3 times and centrifuged at $1,000 \times \mathrm{g}$ at $4^{\circ} \mathrm{C}$ for $5 \mathrm{~min}$, then resuspended in $200 \mu \mathrm{l}$ binding buffer at a concentration of $1 \times 10^{6}$ cells/ml. Annexin V-FITC and PI (10 $\mu \mathrm{l}$ each) was added and the cells were incubated for $30 \mathrm{~min}$ at $4^{\circ} \mathrm{C}$ in the dark. The apoptotic rate was detected using flow cytometry (NovoCyte; Agilent Technologies, Inc.), and the data were analyzed using CytExpert software (version 2.0; Beckman Coulter, Inc.).

$R N A$ extraction and reverse transcription-quantitative $P C R$ $(R T-q P C R)$. Total RNA was extracted from the cultured cells using TRIzol ${ }^{\circledR}$ (Invitrogen; Thermo Fisher Scientific, Inc.) according to the manufacturer's instructions. The RNA concentration was measured using a spectrophotometer (Thermo Fisher Scientific, Inc.) and total RNA (500 ng) was reverse transcribed into cDNA at a final volume of $10 \mu \mathrm{l}$ using oligodT primers and SuperScript II reverse transcriptase (Invitrogen; Thermo Fisher Scientific, Inc.). qPCR was performed using the SYBR Green reaction mix (Qiagen Corporation) and analyzed using a Roche LightCycler system (Roche Diagnostics). The following thermocycling conditions were used: Initial denaturation at $95^{\circ} \mathrm{C}$ for $3 \mathrm{~min}$; followed by 39 cycles at $95^{\circ} \mathrm{C}$ for 
$5 \mathrm{sec}, 56^{\circ} \mathrm{C}$ for $10 \mathrm{sec}, 72^{\circ} \mathrm{C}$ for $25 \mathrm{sec} ; 65^{\circ} \mathrm{C}$ for $5 \mathrm{sec}$, and $95^{\circ} \mathrm{C}$ for $50 \mathrm{sec}$ for the final step. The results were normalized to GAPDH expression levels and the primer sequences are listed in Table I. The RT-qPCR data were analyzed relative to the cycle threshold values and are shown as the fold change $\left(2^{-\Delta \Delta C q}\right)(22)$. The qPCR reaction was performed in triplicate for each sample.

Western blot analysis. The cells were washed with PBS and lysed using radioimmunoprecipitation assay buffer (Invitrogen; Thermo Fisher Scientific, Inc.) supplemented with a protease inhibitor cocktail (Roche Diagnostics). The protein concentration was calculated using a bicinchoninic acid protein assay kit (cat. no. PAB180007; Bioswamp; Wuhan Bienle Biotechnology Co., Ltd.). Equivalent quantities of protein $(30 \mu \mathrm{g})$ from each sample were separated using 12\% SDS-PAGE, transferred to a polyvinylidene fluoride membrane, blocked with $5 \%$ skimmed milk for $2 \mathrm{~h}$, at $4^{\circ} \mathrm{C}$, then incubated with the following specific primary antibodies: minichromosome maintenance proteins (MCMP; cat. no. PAB35600; 1:1,000; Bioswamp; Wuhan Bienle Biotechnology Co., Ltd.), recombinant Ki-67 (Ki-67; cat. no. PAB30684; 1:1,000; Bioswamp; Wuhan Bienle Biotechnology Co., Ltd.), proliferating cell nuclear antigen (PCNA; cat. no. PAB30083; 1:1,000; Bioswamp; Wuhan Bienle Biotechnology Co., Ltd.), cyclin D (cat. no. ab134175; 1:1,000; Abcam), cyclin E (cat. no. ab71535; 1:2,000; Abcam), cyclin-dependent kinase 2 (CDK2; cat. no. MAB37188; 1:1,000; Bioswamp; Wuhan Bienle Biotechnology Co., Ltd.), P57 (cat. no. ab199254; 1:5,000; Abcam), P-gp (cat. no. PAB36768; 1:1,000; Bioswamp; Wuhan Bienle Biotechnology Co., Ltd.), MRP1 (cat. no. PAB33537; 1:1,000; Bioswamp; Wuhan Bienle Biotechnology Co., Ltd.), ABCG2 (cat. no. PAB34152; 1:1,000; Bioswamp; Wuhan Bienle Biotechnology Co., Ltd.), or GAPDH (cat. no. PAB36264; 1:5,000; Bioswamp; Wuhan Bienle Biotechnology Co., Ltd.), overnight at $4^{\circ} \mathrm{C}$. The membranes were then washed with TBS and incubated with goat anti-rabbit IgG secondary antibody (cat. no. SAB43711; 1:10,000; Bioswamp; Wuhan Bienle Biotechnology Co., Ltd.) for $2 \mathrm{~h}$, at $4^{\circ} \mathrm{C}$. An enhanced chemiluminescence kit (Pierce; Thermo Fisher Scientific, Inc.) was used to detect the specific bands and analyzed using Tanon GIS software (version 4.2; Tanon Science and Technology Co., Ltd.) using GAPDH as a control.

Cellular MDR assay. MDR was evaluated using a MDR assay kit (Calcein AM; cat no. 600370, Cayman Chemical Company) following the manufacturer's instructions. The cells were seeded into 96 -well plates $\left(5 \times 10^{4}\right.$ cells/well in $100 \mu \mathrm{l}$ culture medium [RPMI-1640 supplemented with 10\% FBS)] and incubated overnight at $37^{\circ} \mathrm{C}$ with $5 \% \mathrm{CO}_{2}$. The cells were then centrifuged for $5 \mathrm{~min}$ at $300 \mathrm{xg}$ and $4^{\circ} \mathrm{C}$ and the medium was replaced with $100 \mu \mathrm{l}$ culture medium (RPMI-1640 supplemented with $10 \% \mathrm{FBS}$ ). After incubation at $37^{\circ} \mathrm{C}$ with $5 \% \mathrm{CO}_{2}$ for $30 \mathrm{~min}, 100 \mu \mathrm{l}$ Calcein AM solution was added to each sample, followed by a further $30 \mathrm{~min}$ incubation. After centrifugation for $5 \mathrm{~min}$ at $300 \mathrm{x} \mathrm{g}$ and $4^{\circ} \mathrm{C}$, the supernatant was replaced with $200 \mu \mathrm{l}$ ice-cold medium and this step was repeated for a 2 nd time. The samples were immediately viewed under a fluorescent microscope (x200). The cells with decreased MDR displayed strong green fluorescence intensity, indicative of calcein AM-positivity.
Table I. Primer sequences used for quantitative PCR.

\begin{tabular}{ll}
\hline Gene & \multicolumn{1}{c}{ Primer sequence (5'-3') } \\
\hline p38 F & CCATGTTCAGTTCCTTATCTACC \\
p38 R & CCGAGCCAGTCCAAAATC \\
MCMP F & GTTGGTAGGCGTGGAA \\
MCMP R & GGATTTGCGAGGTAGAA \\
Ki-67 F & GCCTCCTAATACGC \\
Ki-67 R & GTGCCTTCACTTCC \\
PCNA F & CAAGAAGGTGTTGGAGGCA \\
PCNA R & TCGCAGCGGTAGGTGTC \\
Cyclin D F & GCGAGGAACAGAAGTGC \\
Cyclin D R & GAGTTGTCGGTGTAGATGC \\
Cyclin E F & ATGTTGACTGCCTTGAA \\
Cyclin E R & CCACTGATACCCTGAAA \\
P57 F & GCACCCAGACACGATC \\
P57 R & CCTCCGACACGAACAC \\
CDK2 F & GAGTTACTTCTATGCCTGAT \\
CDK2 R & GGGTACTGGCTTGGTC \\
Bax F & TTTTGCTTCAGGGTTTCA \\
Bax R & CACTCGCTCAGCTTCTTG \\
Bcl-2 F & CTGGTGGACAACATCGC \\
Bcl-2 R & GGAGAAATCAAACAGAGGC \\
Caspase 3 F & ACATCTCGGTCTGGT \\
Caspase 3 R & GAAACATCACGCATC \\
Caspase 8 F & TTCAGGCTTGTCAGGG \\
Caspase 8 R & CAGGGTTTCGGTAGGA \\
GAPDH F & CCACTCCTCCACCTTTG \\
GAPDH R & CACCACCCTGTTGCTGT \\
\hline & \\
\hline
\end{tabular}

$\mathrm{F}$, forward; $\mathrm{R}$, reverse.

Akt activity assay. Akt activity was detected using an Akt Activity Assay kit (cat. no. KA0885; Abnova), following the manufacturer's instructions. The cells were washed once with PBS and lysed with $200 \mu \mathrm{l}$ ice-cold kinase extraction buffer for $5 \mathrm{~min}$. After centrifugation for $10 \mathrm{~min}$ at $16,100 \mathrm{x} \mathrm{g}$ and $4^{\circ} \mathrm{C}, 2 \mu \mathrm{l} \mathrm{Akt}$ antibody (one of the Akt Activity Assay kit) was added to $200 \mu \mathrm{l}$ cell lysate followed by rotation for $45 \mathrm{~min}$ at $4^{\circ} \mathrm{C}$. The lysate was resuspended in protein A sepharose by gentle vortexing into a slurry. Then, $50 \mu \mathrm{l}$ protein A-sepharose slurry was added to each sample followed by continuous rotation for $1 \mathrm{~h}$, at $4^{\circ} \mathrm{C}$. Following centrifugation at $21,400 \times \mathrm{g}$ for $2 \mathrm{~min}$ at $4^{\circ} \mathrm{C}$, the supernatant was removed and the protein $\mathrm{A}$ beads were washed twice with kinase extraction buffer $(0.5 \mathrm{ml})$ and once with kinase assay buffer $(0.5 \mathrm{ml})$. Next, $50 \mu \mathrm{l}$ kinase assay buffer and $2 \mu \mathrm{l}$ glycogen synthase kinase $3 \alpha$ (GSK-3 $\alpha$ ) protein/ATP mixture was added to the washed protein A beads followed by incubation at $30^{\circ} \mathrm{C}$ for $4 \mathrm{~h}$. The protein A beads were pelleted by centrifugation then, $30 \mu \mathrm{l}$ supernatant was collected in a fresh Eppendorf tube. After the addition of $15 \mu \mathrm{l} 3 \mathrm{X}$ SDS-PAGE buffer, the samples were heated for $3 \mathrm{~min}$ and microcentrifuged $(3,000 \mathrm{x} \mathrm{g})$ for $2 \mathrm{~min}$ at $4^{\circ} \mathrm{C}$ to pellet the protein A beads. The supernatant $(20 \mu \mathrm{l})$ was separated using $12 \%$ SDS-PAGE then, western blot analysis was performed using rabbit phosphophorylated(p)-GSK-3 $\alpha$ (Ser 21) antibody (one of the Akt activity assay kit) at 1:1,000. 
A $37 \mathrm{kDa}$ band corresponding to p-GSK-3 $\alpha$ was detected in the Akt-activated samples.

Statistical analysis. The data are presented as the mean \pm SD. One-way ANOVA followed by a Tukey's post-hoc test was used to compare differences between multiple groups and with the SPSS software (v19.0; IBM Corp.). $\mathrm{P}<0.05$ was used to indicate a statistically significant difference.

\section{Results}

p38 MAPK interference enhances the inhibitory effect of noscapine on SW480/5-FU cell proliferation. The transfection efficiency of si-p38 was analyzed and the results showed that the mRNA expression level of p38 was significantly decreased in the si-p38 group compared with that in the si-NC group, whereas there was no significant difference between the SW480/5-FU and si-NC groups (Fig. 1A). The viability and proliferation of the SW480 and SW480/5-FU cells were evaluated using CCK-8 and colony formation assays, respectively. The viability of the SW480/5-FU cells was significantly decreased by both noscapine treatment and p38 interference alone, and p38 MAPK interference also enhanced the inhibitory effect of noscapine (Fig. 1B). In addition, colony formation was notably suppressed in the noscapine-treated SW480/5-FU cells, and inhibition of p38 MAPK exacerbated this effect (Fig. 1C). Next, the mRNA and protein expression level of proliferation-related genes was examined. This revealed that the mRNA and protein expression levels of MCMP, Ki-67 and PCNA were lower in noscapine-treated SW480/5-FU cells compared with SW580/5-FU cells. The SW480/5-FU cells transfected with p38 MAPK inhibition and treated with noscapine displayed the lowest mRNA and protein expression level of these proliferation-related genes (Fig. 1D and E).

p38 MAPK interference promotes noscapine-induced SW480/5-FU cell cycle arrest. Cell cycle analysis indicated that noscapine treatment induced an increase in the percentage of the SW480/5-FU cells in the $\mathrm{G}_{1}$ phase, which was further increased by p38 MAPK inhibition (Fig. 2A). In addition, the combination of noscapine treatment with p38 interference significantly decreased the mRNA and protein expression level of cyclin D, cyclin E and CDK 2 compared with the SW480/5-FU cells, while increasing the mRNA and protein expression level of P57 in the SW480/5-FU cells (Fig. 2B and C).

p38 MAPK interference promotes noscapine-induced SW480/5-FU cell apoptosis. As shown in Fig. 3A, the combination of p38 interference with noscapine treatment notably increased the percentage of apoptotic SW480/5-FU cells. In addition, noscapine treatment combined with p38 interference significantly decreased mRNA expression level of the anti-apoptotic protein, Bcl-2, and increased the mRNA expression level of the pro-apoptotic proteins, Bax, caspase- 3 and -8 in the SW480/5-FU cells compared with the SW480/5-FU group (Fig. 3B).

p38 MAPK interference regulates the resistance of SW480/5-FU cells to noscapine. Next, MDR was evaluated in the SW480 and SW480/5-FU cells. The notably reduced fluorescence intensity of calcein AM in the SW480/5-FU cells indicated stronger MDR compared with that in the SW480 cells (Fig. 4A). p38 interference significantly increased the calcein AM fluorescence intensity, suggesting that p38 interference inhibited MDR in the SW480/5-FU cells (Fig. 4A).

Furthermore, Akt activity was assessed using an Akt assay and western blot analysis to measure $\mathrm{p}-\mathrm{GSK}-3 \alpha$ protein expression levels (Fig. 4B). Both Akt activity and the protein expression levels of $\mathrm{p}$-GSK-3 $\alpha$ were decreased significantly by both noscapine treatment and p38 MAPK interference in the SW480/5-FU cells compared with the SW480/5-FU group (Fig. 4B). Compared with that in cells treated with noscapine alone, the combination of p38 interference and noscapine treatment resulted in a further decrease in Akt activity and p-GSK-3 $\alpha$ protein expression level.

The expression level of the MDR-related proteins, P-gp, MRP1 and ABCG2 were also detected using western blot analysis (Fig. 4C). Compared with that in untreated SW480 cells, the SW480/5-FU cells showed significantly increased the protein expression level of P-gp, MRP1 and ABCG2. Noscapine treatment decreased the expression of these proteins in the SW480/5-FU cells, and p38 MAPK inhibition further enhanced this effect.

\section{Discussion}

The present study revealed that inhibition of p38 MAPK significantly increased the sensitivity of the 5-FU-resistant SW480 cells to noscapine. When the SW480/5-FU cells were treated with noscapine in combination with p38 interference, cell proliferation and drug resistance were suppressed, and apoptosis was further induced, compared with that in cells treated with noscapine alone. The decrease in cell proliferation was consistent with decreased mRNA and protein expression level of MCMP, Ki-67 and PCNA in the SW480/5-FU cells. In addition, the combination of noscapine treatment with $\mathrm{p} 38$ interference significantly increased the protein expression level of Bax, caspase- 3 and -8 , which are the hallmarks pro-apoptotic proteins (23). Cell cycle arrest was consistent with the increase in the protein and mRNA expression level of P57 and the decrease of cyclin D, cyclin E and CDK2 in the SW480/5-FU cells. Further investigation confirmed that noscapine treatment combined with p38 MAPK inhibition notably inhibited the MDR of the SW480/5-FU cells by decreasing the protein expression level of Akt and inhibiting the protein expression level of the MDR-related proteins, P-gp, MRP1 and ABCG2. These findings suggested that p38 MAPK regulated SW480/5-FU cell survival following noscapine treatment, and that inhibition of p38 MAPK increased the sensitivity and suppressed the resistance of the SW480/5-FU cells to noscapine.

The MAPK pathway is a major signal transduction cascade, that triggers multiple biological cell responses following growth factor treatment or stress stimulation (24). The p38 MAPK pathway is primarily activated in response to environmental stress and is mainly involved in cell growth arrest and apoptosis (25). p38 MAPK can be stimulated by various stresses, including osmotic stress, heat shock, UV irradiation and certain chemotherapeutic drugs, such as cisplatin and doxorubicin (26). Inhibition of p38 MAPK has been reported to downregulate the multidrug-resistance I 

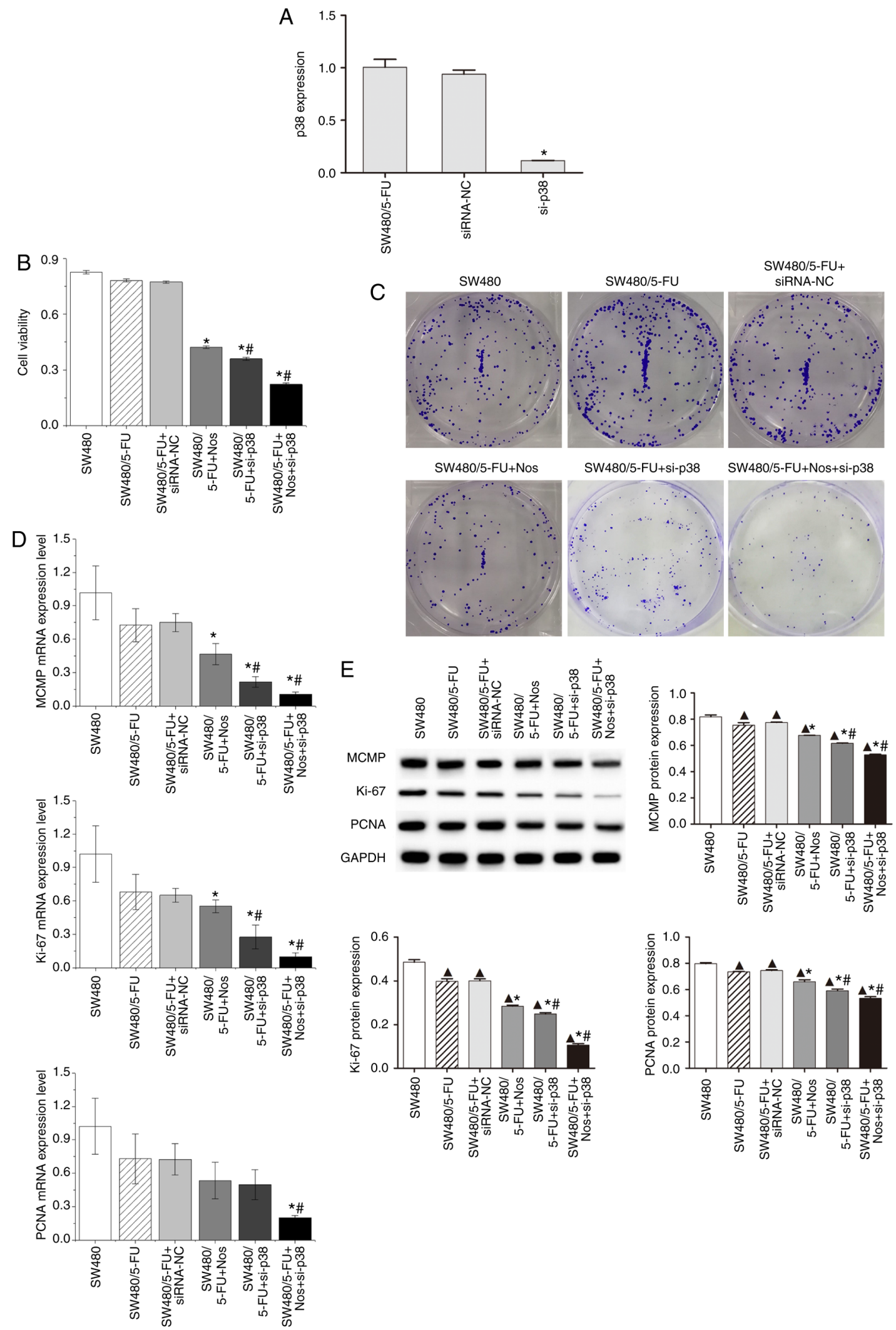

Figure 1. p38 MAPK interference enhances the inhibitory effect of noscapine on the viability and proliferation of the SW480/5-FU cells. (A) Transfection efficiency of si-p38. (B) Cell viability was measured using a Cell Counting Kit-8 assay. (C) Representative images of colony formation in the SW480 and SW480/5-FU cells transfected with si-p38/NC and/or treated with noscapine. (D) mRNA and (E) protein expression level sof MCMP, Ki-67 and PCNA in the SW480 and SW480/5-FU cells transfected with si-p38/NC and/or treated with noscapine. The data are presented as the mean $\pm \mathrm{SD}(\mathrm{n}=3) .{ }^{\mathrm{A}} \mathrm{P}<0.05$ vs. $\mathrm{SW} 480$; ${ }^{\text {*P }}<0.05$ vs. SW480/5-FU; ${ }^{\mathrm{P}}<0.05$ vs. SW480/5-FU+Nos. Nos, noscapine; si, small inhibiting; NC, negative control; 5-FU, 5-fluorouracil.

gene, which has been hypothesized to be responsible for chemoresistance in gastric cancer cells (27). In the present study, the effects of p38 MAPK on the sensitivity of the SW480/5-FU cells to noscapine were investigated. Inhibition 

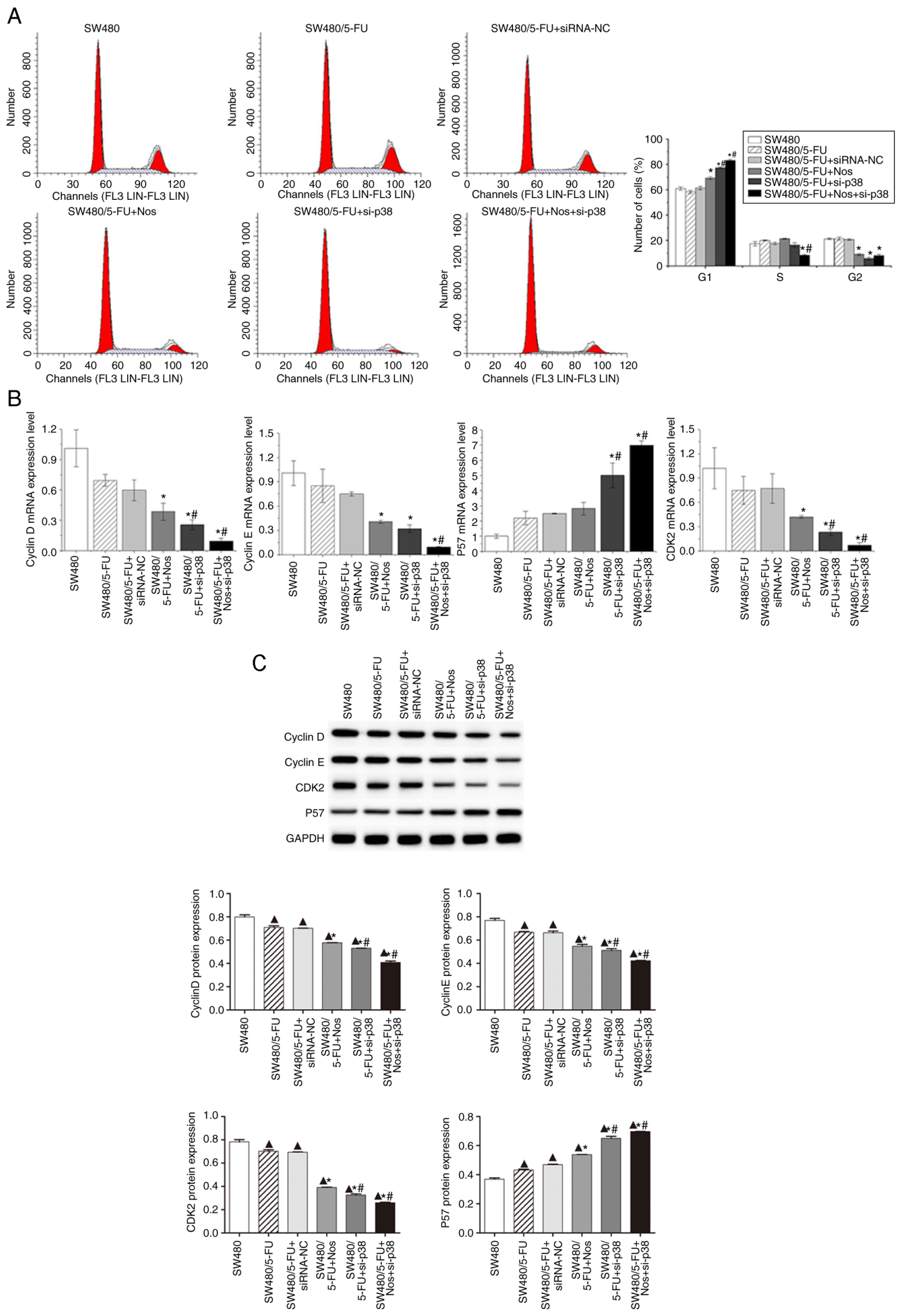

Figure 2. p38 MAPK interference enhances noscapine-induced $\mathrm{G}_{1}$-phase arrest in the SW480/5-FU cells. (A) Cell cycle analysis indicated that p38 MAPK interference enhanced the noscapine-induced increase in the percentage of cells in the $\mathrm{G}_{1}$ phase. (B) mRNA and (C) protein expression level of cyclin D, cyclin E, CDK2 and P57 in the SW480 and SW480/5-FU cells transfected with si-p38/NC and/or treated with noscapine. The data are presented as the mean \pm SD (n=3). ${ }^{\wedge} \mathrm{P}<0.05$ vs. SW480; ${ }^{\mathrm{P}} \mathrm{P}<0.05$ vs. SW480/5-FU; " $\mathrm{P}<0.05$ vs. SW480/5-FU+Nos. Nos, noscapine; si, small inhibiting; NC, negative control; 5-FU, 5-fluorouracil. 

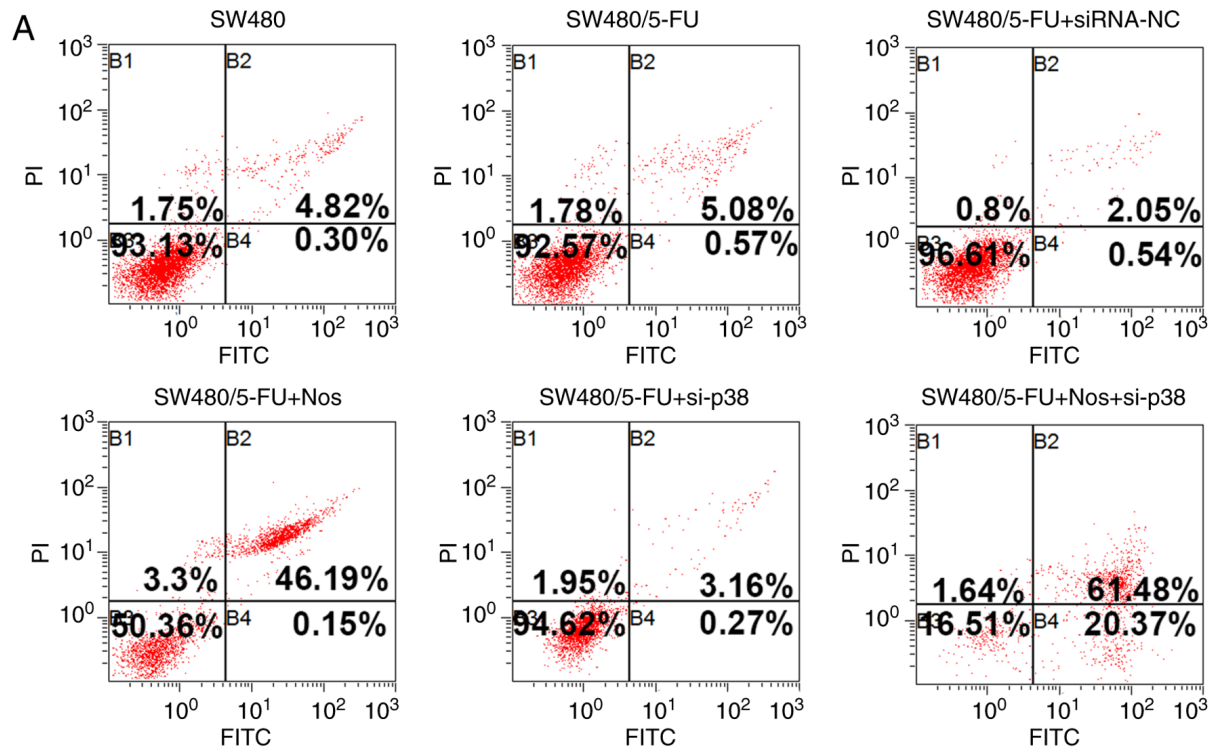

B
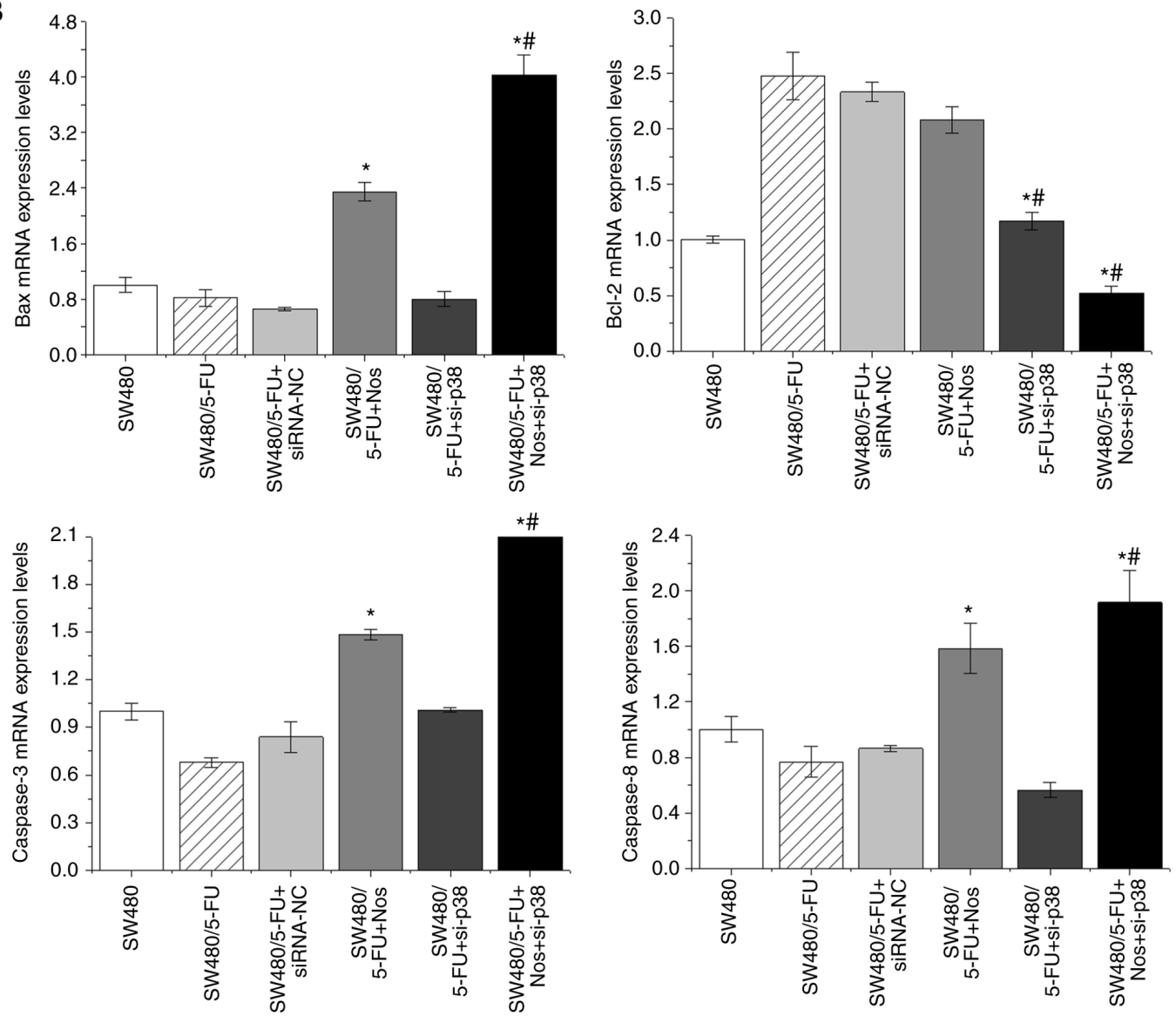

Figure 3.p38 MAPK interference enhances noscapine-induced apoptosis in the SW480/5-FU cells. (A) p38 MAPK interference enhanced the noscapine-induced increase in the percentage of apoptotic SW480/5-FU cells. (B) mRNA expression level of Bax, Bcl-2, caspase-3 and -8 in the SW480 and SW480/5-FU cells transfected with si-p38/NC and/or treated with noscapine. The data are presented as the mean $\pm \mathrm{SD}(\mathrm{n}=3)$. ${ }^{*} \mathrm{P}<0.05$ vs. SW480/5-FU; ${ }^{*} \mathrm{P}<0.05$ vs. SW480/5-FU+Nos. Nos, noscapine; si, small inhibiting; NC, negative control; 5-FU, 5-fluorouracil.

of p38 MAPK markedly enhanced the effect of noscapine in reducing SW480/5-FU cell viability and proliferation, as well as promoting cell cycle arrest and apoptosis.

Bax and Bcl-2 are the principal mediators of mitochondrial membrane permeability (28). The ratio of anti-apoptotic Bcl-2 to pro-apoptotic Bax is a marker of the propensity of cells to undergo apoptosis (29). The results of the present study demonstrated that following treatment of the SW480/5-FU cells with noscapine, in conjunction with p38 MAPK interference, the protein expression level of Bax was increased, while that of Bcl-2 was reduced, modulating the loss of mitochondrial membrane potential and leading to cancer cell death. In addition, it was demonstrated that p38 MAPK interference promoted noscapine-induced cell cycle arrest at the sub- $\mathrm{G}_{1}$ phase in the SW480/5-FU cells. However, 

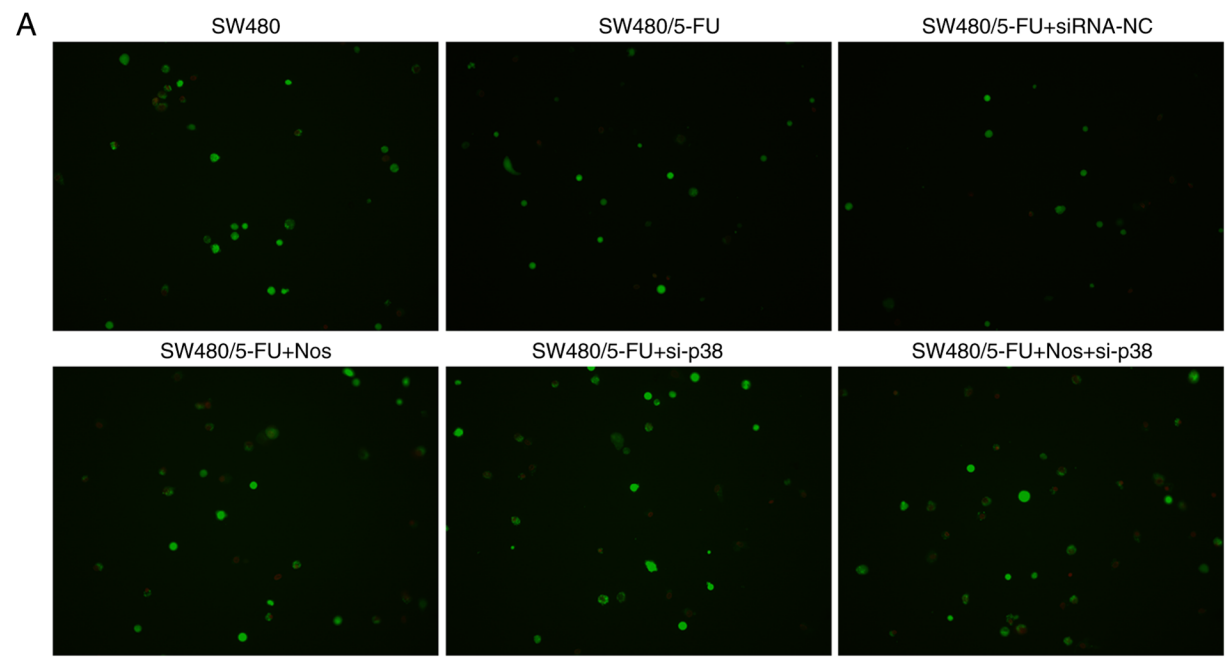

SW480/5-FU+Nos+si-p38

B

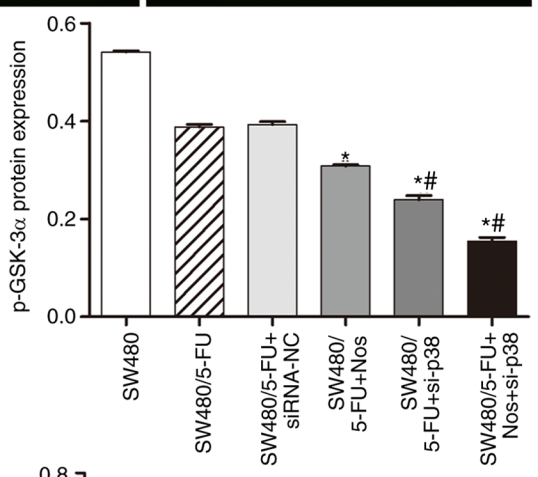

C
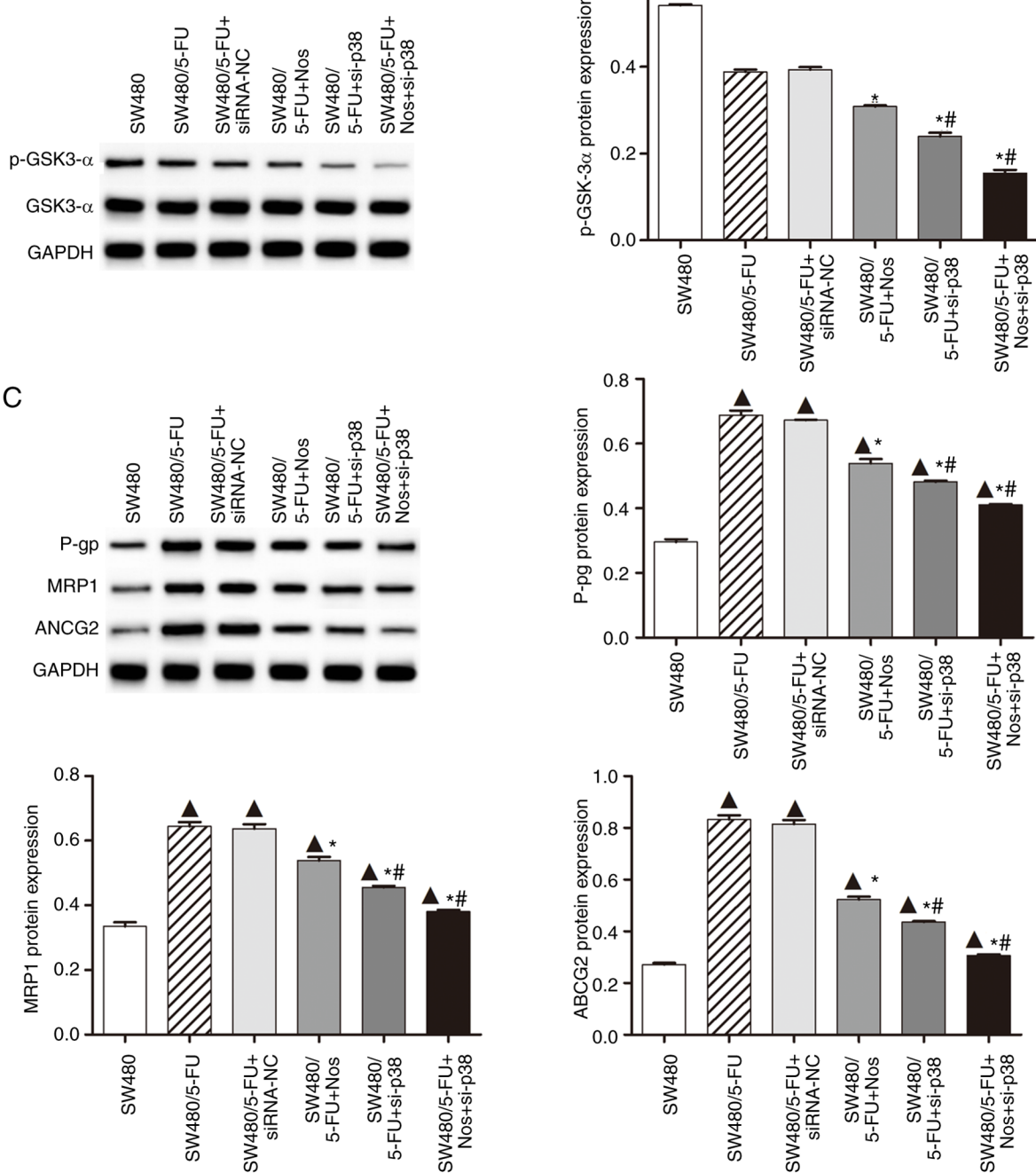

Figure 4. p38 MAPK interference reduced the resistance of SW480/5-FU to noscapine. (A) The MDR of the SW480 and SW480/5-FU cells, transfected with si-p38/NC and/or treated with noscapine, was detected using a Multi-Drug Resistance Assay kit (calcein AM). Fluorescent images of the SW480/5-FU cells stained with calcein AM (green) are shown. Magnification, x200. (B) Akt activity was detected using an Akt Activity Assay kit and the protein expression level of p-GSK-3 $\alpha$ was measured using western blot analysis. (C) Protein expression level of the MDR-related proteins P-gp, MRP1 and ABCG2 was detected using western blot analysis. The data are presented as the mean $\pm \mathrm{SD}(\mathrm{n}=3)$. ${ }^{\wedge} \mathrm{P}<0.05$ vs. SW480; ${ }^{*} \mathrm{P}<0.05$ vs. SW480/5-FU; " $\mathrm{P}<0.05$ vs. SW480/5-FU+Nos. MDR, multidrug resistance; Nos, noscapine; si, small inhibiting; NC, negative control; 5-FU, 5-fluorouracil; p, phosphorylated.

Jeon et al (30) previously reported that p38 MAPK inhibition reduced nitric oxide-induced cell cycle arrest in the $\mathrm{G}_{0} / \mathrm{G}_{1}$ phase in the colon cancer cell line, SW620. This suggested that this pathway may be associated with the change in drug resistance.
Noscapine has been reported to have in vitro anticancer activity for various neoplasia's, such as myeloid leukemia, glioma and prostate cancer $(31,32)$, and animal experiments have shown that its oral administration $(120 \mathrm{mg} / \mathrm{kg} / \mathrm{d}$ or 
$300 \mathrm{mg} / \mathrm{kg} / \mathrm{d}$ ) has minimal adverse side effects on organs, such as the heart, kidney and thymus (10,33). Noscapine has also been shown to enhance the cytotoxicity of chemotherapeutic agents against various tumor cells, effectively inhibiting tumor growth. However, the molecular mechanisms underlying these antitumor effects are unclear. It has been reported that noscapine promoted cisplatin-induced apoptosis in drug-resistant ovarian cancer cells by controlling the cell cycle, decreased anti-apoptotic factors, and increased pro-apoptotic factors to consequently inhibit tumor growth (34). Furthermore, Doddapaneni et al (35) have reported that noscapine increased the sensitivity of xenografts to docetaxel, which lead to increased apoptosis and decreased resistance of triple-negative breast cancer by modulating key MDR regulators. MDR transporters pump cytotoxic drugs out of cancer cells, thereby decreasing their intracellular levels and enhancing tumor cell survival. Therefore, inhibition of P-gp, MRP1 and ABCG2 could resensitize multidrug-resistant cells to anticancer drugs (36). Previous studies have demonstrated that the MAPK pathway plays an important role in MDR and is a promising target for systemic therapy $(37,38)$. Zhou et al (39) reported that inhibition of p38 MAPK reversed MDR in breast cancer cells by decreasing protein $\mathrm{P}-\mathrm{gp}$ expression. Specifically, p38 MAPK has been associated with cancer cell apoptosis, and multidrug-resistant cells showed high levels of p38 phosphorylation. In the present study, it was found that p38 MAPK inhibition suppressed the resistance of the SW480/5-FU cells to noscapine by decreasing the protein expression level of the MDR-related proteins, P-gp, MRP1 and ABCG2. This was consistent with inhibition of Akt activation and decreased protein expression levels of p-GSK-3 $\alpha$. These results indicated that noscapine might alleviate the drug resistance of the SW480/5-FU cells via the p38 MAPK signaling pathway.

In the present study, in vivo experiments were not performed, which is a limitation and will be performed in future research. In addition, it will also be investigated the underlying mechanism of noscapine and si-p38.

In conclusion, the results from the present study demonstrated that inhibition of p38 MAPK increased the sensitivity of the SW480/5-FU cells to noscapine by inhibiting cell proliferation and inducing cell cycle arrest and apoptosis. Furthermore, inhibition of p38 MAPK increased noscapine-induced cytotoxicity in the SW480/5-FU cells by decreasing P-gp, MRP1 and ABCG2 protein expression level, thereby reversing MDR. The present study indicated that p38 MAPK could be a potential therapeutic target for patients with colon cancer demonstrating drug resistance.

\section{Acknowledgements}

Not applicable.

\section{Funding}

The present study was supported by the Project of Health and Family Planning Commission of Wuhan Municipality (grant no. WX17B05), Major project of Wuhan Health Commission (grant no. WX20M01), Hubei Province Natural Science Foundation of China (grant nos.2018CFB725 and 2019CFB749) and the Hubei Province Local Guidance Technological Development Project (grant no. 2019ZYYD067).

\section{Availability of data and materials}

The datasets used and analyzed during the current study are available from the corresponding author upon reasonable request.

\section{Authors' contributions}

$\mathrm{ZH}, \mathrm{XT}, \mathrm{QZ}$ and XC contributed to the conception of the study. $\mathrm{ZH}, \mathrm{XH}, \mathrm{SH}, \mathrm{JT}$ and LM designed and performed the experiments, analyzed the data and drafted the initial manuscript. WL, WC, YZ, YC, AC, TZ and MH analyzed the data and provided technical support. TZ and $\mathrm{MH}$ assisted with the analysis and with constructive discussions. All authors read and approved the final manuscript. ZH, LM, XH, JT, WL, WC, YZ, YC, SH, AC, TZ, MH, XC, XT and QZ confirmed the authenticity of all the raw data.

\section{Ethics approval and patient consent to participate}

Not applicable.

\section{Patient consent for publication}

Not applicable.

\section{Competing interests}

The authors declare that they have no competing interests.

\section{References}

1. Ferlay J, Soerjomataram I, Dikshit R, Eser S, Mathers C, Rebelo M, Parkin DM, Forman D and Bray F: Cancer incidence and mortality worldwide: Sources, methods and major patterns in GLOBOCAN 2012. Int J Cancer 136: E359-E386, 2015.

2. Zhang $\mathrm{L}$ and $\mathrm{Yu} \mathrm{J}$ : Role of apoptosis in colon cancer biology, therapy, and prevention. Curr Colorectal Cancer Rep: Oct 1, 2013 (Epub ahead of print). doi: 10.1007/s11888-013-0188-z.

3. Siegel RL, Miller KD, Fedewa SA, Ahnen DJ, Meester RG, Barzi A and Jemal A: Colorectal cancer statistics, 2017. CA Cancer J Clin 67: 177-193, 2017.

4. Imai Y, Ishikawa E, Asada S and Sugimoto Y: Estrogen-mediated post transcriptional down-regulation of breast cancer resistance protein/ABCG2. Cancer Res 65: 596-604, 2005.

5. Mutoh K, Tsukahara S, Mitsuhashi J, Katayama K and Sugimoto Y: Estrogen-mediated post transcriptional down-regulation of P-glycoprotein in MDR1-transduced human breast cancer cells. Cancer Sci 97: 1198-1204, 2006

6. Xia YZ, Yang L, Xue GM, Zhang C, Guo C, Yang YW, Li SS, Zhang LY, Guo QL and Kong $\approx$ LY: Combining GRP78 suppression andMK2206-induced Aktinhibition decreases doxorubicin-induced P-glycoprotein expression and mitigates chemoresistance in human osteosarcoma. Oncotarget 7: 56371-56382, 2016.

7. Sasaki K, Tsuno NH, Sunami E, Tsurita G, Kawai K, Nishikawa T, Shuno Y, Hongo K, Hiyoshi M, Kaneko M, et al: Chloroquine potentiates the anti-cancer effect of 5-fluorouracil on colon cancer cells. BMC Cancer 10: 370, 2010.

8. Tentes IK, Schmidt WM, Krupitza G, Steger GG, Mikulits W Kortsaris A and Mader RM: Long-term persistence of acquired resistance to 5-fluorouracil in the colon cancer cell line SW620. Exp Cell Res 316: 3172-3181, 2010.

9. Chandra R, Madan J, Singh P, Chandra A, Kumar P, Tomar V and Dass SK: Implications of nanoscale based drug delivery systems in delivery and targeting tubulin binding agent, noscapine in cancer cells. Curr Drug Metab 13: 1476-1483, 2012. 
10. Ye K, Ke Y, Keshava N, Shanks J, Kapp JA, Tekmal RR, Petros J and Joshi HC: Opium alkaloid noscapine is an antitumor agent that arrests metaphase and induces apoptosis in dividing cells. Proc Natl Acad Sci USA 95: 1601-1606, 1998.

11. Aneja R, Vangapandu SN, Lopus M, Viswesarappa VG, Dhiman N, Verma A, Chandra R, Panda D and Joshi HC: Synthesis of microtubule-interfering halogenated noscapine analogs that perturb mitosis in cancer cells followed by cell death. Biochem Pharmacol 72: 415-426, 2006.

12. Zhou J, Liu M, Luthra R, Jones J, Aneja R, Chandra R, Tekmal RR and Joshi HC: EM012, a microtubule-interfering agent, inhibits the progression of multidrug-resistant human ovarian cancer both in cultured cells and in athymic nude mice. Cancer Chemother Pharmacol 55: 461-465, 2005.

13. Liu M, Luo XJ, Liao F, Lei XF and Dong WG: Noscapine induces mitochondria-mediated apoptosis in gastric cancer cells in vitro and in vivo. Cancer Chemother Pharmacol 67: 605-612, 2011

14. Yang ZR, Liu M, Peng XL, Lei XF, Zhang JX and Dong WG: Noscapine induces mitochondria-mediated apoptosis in human colon cancer cells in vivo and in vitro. Biochem Biophys Res Commun 421: 627-633, 2012

15. Landen JW, Lang R, McMahon SJ, Rusan NM, Yvon AM, Adams AW, Sorcinelli MD, Campbell R, Bonaccorsi P, Ansel JC, et al: Noscapine alters microtubule dynamics in living cells and inhibits the progression of melanoma. Cancer Res 62: 4109-4114, 2002.

16. Ke Y, Ye K, Grossniklaus HE, Archer DR, Joshi HC and Kapp JA: Noscapine inhibits tumor growth with little toxicity to normal tissues or inhibition of immune responses. Cancer Immunol Immunother 49: 217-225, 2000.

17. Ohtsubo K, Yamada T, Zhao L, Jin TF, Takeuchi S, Mouri H, Yamashita K, Yasumoto K, Fujita N, Kitagawa H, et al: Expression of Akt kinase-interacting protein 1, a scaffold protein of the PI3K/PDK1/Akt pathway, in pancreatic cancer. Pancreas 43: 1093-1100, 2014.

18. Xu R, Sato N, Yanai K, Akiyoshi T, Nagai S, Wada J, Koga K, Mibu R, Nakamura M and Katano M: Enhancement of paclitaxel-induced apoptosis by inhibition of mitogen-activated protein kinase pathway in colon cancer cells. Anticancer Res 29: 261-270, 2009

19. Kuno Y, Kondo K, Iwata H, Senga T, Akiyama S, Ito K, Takagi H and Hamaguchi M: Tumor-specific activation of mitogen-activated protein kinase in human colorectal and gastric carcinoma tissues Jpn J Cancer Res 89: 903-909, 1998.

20. Yang SY, Miah A, Sales KM, Fuller B, Seifalian AM and Winslet M: Inhibition of the p38 MAPK pathway sensitises human colon cancer cells to 5-fluorouracil treatment. Int J Oncol 38: 1695-1702, 2011.

21. Dinicola S, Pasqualato A, Proietti S, Masiello MG, Palombo A, Coluccia P, Canipari R, Catizone A, Ricci G, Harrath H, et al: Paradoxical E-cadherin increase in 5FU-resistant colon cancer is unaffected during mesenchymal-epithelial reversion induced by gamma-secretase inhibition. Life Sci 145: 174-183, 2016.

22. Livak KJ and Schmittgen TD: Analysis of relative gene expression data using real-time quantitative PCR and the 2(- $\Delta \Delta \mathrm{C}(\mathrm{T}))$ method. Methods 25: 402-408, 2001.

23. Tamm I, Wang Y, Sausville E, Scudiero DA, Vigna N, Oltersdorf T and Reed JC: IAP-family protein survivin inhibits caspase activity and apoptosis induced by Fas (CD95), Bax, caspases, and anticancer drugs. Cancer Res 58: 5315-5320, 1998.

24. Fang JY and Richardson BC: The MAPK signalling pathways and colorectal cancer. Lancet Oncol 6: 322-327, 2005.
25. Mansouri A, Ridgway LD, Korapati AL, Zhang Q, Tian L, Wang Y, Siddik ZH, Mills GB and Claret FX: Sustained activation of JNK/p38 MAPK pathways in response to cisplatin leads to Fas ligand induction and cell death in ovarian carcinoma cells. J Biol Chem 278: 19245-19256, 2003.

26. Chang L and Karin M: Mammalian MAP kinase signalling cascades. Nature 410: 37-40, 2001.

27. Guo X, Ma N, Wang J, Song J, Bu X, Cheng Y, Sun K, Xiong H, Jiang G, Zhang B, et al: Increased p38-MAPK is responsible for chemotherapy resistance in human gastric cancer cells. BMC Cancer 8: 375, 2008.

28. Durai R, Yang SY, Sales KM, Seifalian AM, Goldspink G and Winslet MC: Insulin-like growth factor binding protein-4 gene therapy increases apoptosis by altering Bcl-2 and Bax proteins and decreases angiogenesis in colorectal cancer. Int J Oncol 30: 883-888, 2007.

29. Zamzami N, Brenner C, Marzo I, Susin SA and Kroemer G: Subcellular and submitochondrial mode of action of Bcl-2-like oncoproteins. Oncogene 16: 2265-2282, 1998.

30. Jeon HK, Choi SU and Jung NP: Association of the ERK1/2 and p38 kinase pathways with nitric oxide-induced apoptosis and cell cycle arrest in colon cancer cells. Cell Biol Toxicol 21: 115-125, 2005.

31. Tomar V, Kukreti S, Prakash S, Madan J and Chandra R: Noscapine and its analogs as chemotherapeutic agent: Current updates. Curr Top Med Chem 17: 174-188, 2017.

32. DeBono A, Capuano B and Scammells PJ: Progress toward the development of noscapine and derivatives as anticancer agents. J Med Chem 58: 5699-5727, 2015.

33. Chougule MB, Patel AR, Jackson T and Singh M: Antitumor activity of Noscapine in combination with Doxorubicin in triple negative breast cancer. PLoS One 6: e17733, 2011.

34. Shen W, Liang B, Yin J, Li X and Cheng J: Noscapine Increases the sensitivity of drug-resistant ovarian cancer cell line SKOV3/DDP to cisplatin by regulating cell cycle and activating apoptotic pathways. Cell Biochem Biophys 72: 203-213, 2015.

35. Doddapaneni R, Patel K, Chowdhury N and Singh M: Reversal of drug-resistance by noscapine chemo-sensitization in docetaxel resistant triple negative breast cancer. Sci Rep 7: 15824, 2017.

36. Peck RA, Hewett J, Harding MW, Wang YM, Chaturvedi PR, Bhatnagar A, Ziessman H, Atkins F and Hawkins MJ: Phase I and pharmacokinetic study of the novel MDR1 and MRP1 inhibitor biricodar administered alone and in combination with doxorubicin. J Clin Oncol 19: 3130-3141, 2001

37. Cuadrado A and Nebreda AR: Mechanisms and functions of p38 MAPK signalling. Biochem J 429: 403-417, 2010.

38. Katayama K, Yoshioka S, Tsukahara S, Mitsuhashi J and Sugimoto Y: Inhibition of the mitogen-activated protein kinase pathway results in the down-regulation of P-glycoprotein. Mol Cancer Ther 6: 2092-2102, 2007.

39. Zhou XW, Xia YZ, Zhang YL, Luo JG, Han C, Zhang H, Zhang C, Yang L and Kong LY: Tomentodione $M$ sensitizes multidrug resistant cancer cells by decreasing P-glycoprotein via inhibition of p38 MAPK signaling. Oncotarget 8: 101965-101983, 2017.

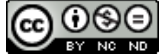

This work is licensed under a Creative Commons Attribution-NonCommercial-NoDerivatives 4.0 International (CC BY-NC-ND 4.0) License. 